\title{
Teorias da tradução e o ensino de língua estrangeira
}

\author{
Sinara de Oliveira Branco (BRANCO, Sinara O.) \\ Professora Doutora da Universidade Federal de Campina Grande - UFCG \\ sinarabranco@gmail.com
}

\section{Resumo}

Este trabalho tem o objetivo de identificar o uso de estratégias de tradução por alunos da habilitação em língua inglesa, em nível intermediário, do Curso de Letras da UFCG, de acordo com as Estratégias de Tradução de Chesterman (1997), as categorias de tradução de Jakobson (1958/2000) e a visão de Gutt (2000) sobre a tradução como uso interpretativo interlingual. Tal investigação apresenta um estudo comparativo entre as línguas inglesa e portuguesa buscando contribuir para um maior desenvolvimento do conhecimento sintático, semântico e pragmático dos alunos em ambas as línguas. Este estudo segue a orientação de Albir (1998), que acredita que o uso da tradução em sala de aula inclui dois aspectos: i) tradução interiorizada - feita por todo aprendiz de línguas estrangeiras; e ii) tradução pedagógica - utilizada em sala de aula como ferramenta pedagógica para reforçar e verificar a aprendizagem utilizando textos, análise contrastiva e reflexão. A tradução será considerada uma atividade comunicativa que auxilia no ensino tanto de línguas estrangeiras quanto de tradução, bem como no aprimoramento do conhecimento da língua materna e da língua inglesa através do uso de interlíngua.

Palavras-chave: estudos da tradução, ensino de línguas, estratégias de tradução, análise contrastiva.

\begin{abstract}
The aim of this paper is to identify the use of translation strategies by Letras students from UFCG, majoring in English, at intermediate level, using Chesterman's (1997) translation strategies, Jakobson's (1958/2000) translation categories and Gutt's (2000) view of translation as an interlingual interpretative use of language. This is a comparative study of English and Brazilian Portuguese, designed to contribute to greater development of knowledge in syntactic, semantic and pragmatic terms in both languages. The theoretical framework of the study is based on Albir (1998), who believes that translation is used in the classroom in two ways: i) interiorised translation - used by any foreign language learner; and ii) pedagogic translation - used in the classroom as a pedagogic tool to reinforce and assess learning through texts, contrastive analysis and reflection. Translation is considered a communicative activity that assists in the teaching of foreign languages and of translation per se. Translation also helps improve knowledge of the mother tongue and the foreign language, through the use of interlanguage.
\end{abstract}

Keywords: Translation studies, foreign language teaching, translation strategies, contrastive analysis. 


\section{Considerações iniciais}

A tradução, em um sentido mais amplo, pode ser definida como uma operação de transmissão de mensagem de um sistema linguístico para outro. Tal atividade foi utilizada como ferramenta para o ensino de Latim durante a Idade Média, direcionada a atividades de leitura. Esta foi a origem do Método de Ensino Gramática e Tradução, que, segundo Leffa (1988), funcionava da seguinte forma: i) o professor dava explicações utilizando a língua materna dos alunos; ii) os alunos memorizavam uma lista de palavras em Latim; iii) os alunos aprendiam regras linguísticas para relacionar as palavras memorizadas em frases; e iv) os alunos faziam exercícios de tradução. O principal objetivo do método era capacitar os alunos a lerem textos literários e religiosos. No século XIX, o Método Gramática e Tradução foi deixado de lado, pois outras línguas começaram a ser estudadas e a comunicação falada tornou-se essencial no aprendizado de línguas estrangeiras. Perdeu-se, nesta fase, a importância ou utilidade da tradução, como usada no Método Gramática e Tradução, para o ensino de línguas estrangeiras. Entretanto, atualmente, a tradução está retornando, sutilmente, à sala de aula e a atenção está voltada para como ela pode ser utilizada de maneira positiva no contexto de ensino de línguas estrangeiras.

Autores como Malmkjaer (1998) e Lucindo (1997), por exemplo, classificam a tradução como uma atividade comunicativa, que oferece oportunidade a vários usos distintos, como ensinar a traduzir, aprimorar o conhecimento da língua materna e da língua estrangeira, nesse caso, do inglês, através da Análise Contrastiva, e aprimorar habilidades de leitura. Conforme Lucindo (1997), o uso da tradução em sala de aula torna os alunos mais ativos e eles passam a participar mais das atividades em sala de aula. Albir (1998), por sua vez, acredita que o uso da tradução em sala de aula inclui dois aspectos: i) tradução interiorizada - feita por todo aprendiz de língua estrangeira; e ii) tradução pedagógica - utilizada em sala de aula como ferramenta pedagógica para reforçar e verificar a aprendizagem utilizando textos, análise contrastiva e reflexão. A tradução pode ainda ser utilizada como atividade para explicação de conteúdo específico ou como exercício. Entretanto, seu uso nesses casos deve ser controlado e restrito a determinadas situações. Os autores mencionados acima alertam ainda para que tenhamos o cuidado de utilizar a tradução em contextos específicos, e não traduzir 
palavras ou frases isoladas, gerando falta de sentido e, consequentemente, de comunicação.

Albir (1988) diz que, como exercício, a tradução está dividida em três fases: i) compreensão, entendimento da ideia do texto; ii) 'esquecimento' das palavras, desverbalizando o texto, mas tendo em mente o significado; e iii) escolha da melhor forma de re-expressar tal texto na língua-alvo, mantendo a mensagem do texto original o mais próximo possível do texto-alvo. Tais atividades devem ainda envolver aspectos linguísticos e não linguísticos para que os alunos percebam a necessidade de mudar e adequar a linguagem a cada texto e situação. A intenção é de desenvolver o léxico, a visão crítica de língua e aspectos culturais das línguas envolvidas.

Seguindo as ideias expostas previamente, Costa (1988) ressalta que, ao usar a tradução em sala de aula, o professor deve levar em consideração alguns pontos: i) a orientação da tradução; ii) a tradução oral e escrita; e iii) a sua utilização como procedimento de aprendizado e/ou avaliação. O autor diz ainda que a tradução deve ser considerada como uma quinta habilidade, associada à fala, escuta, leitura e escrita, e que o ensino de línguas pode ganhar uma perspectiva cultural, ajudando a identificar dificuldades de aprendizagem relacionadas a aspectos culturais das línguas.

A partir de tais pontos e aplicando procedimentos que sigam as ideias sugeridas acima, este trabalho tem o objetivo de identificar quais estratégias de tradução são utilizadas, inconscientemente, pelos alunos de língua inglesa de nível intermediário do Curso de Letras - habilitação em língua inglesa da Universidade Federal de Campina Grande (UFCG), em textos escritos em inglês, de acordo com a Abordagem Funcionalista da Tradução.

Para atingir tal objetivo, em um primeiro momento, os alunos são observados em sala de aula e suas atividades escritas em língua inglesa são analisadas para que, posteriormente, seja possível investigar quais estratégias de tradução foram utilizadas por eles ao se comunicarem em língua inglesa. A possibilidade é que, a princípio, eles utilizem estratégias relacionadas à interlíngua, recorrendo também ao uso de neologismos e estrangeirismos.

Tal estudo está em fase de desenvolvimento como Projeto de Pesquisa da PósGraduação em Linguagem e Ensino da Unidade Acadêmica de Letras da UFCG, visando desenvolver um estudo comparativo das duas línguas que contribua para um maior conhecimento sintático, semântico e pragmático das estruturas identificadas, 
oferecendo uma melhor comunicação - oral e escrita - entre professores e alunos. Neste caso, acrescento o comentário de Medgyes (1994) sobre o fato de que, como professores e falantes não nativos do inglês, devemos desenvolver três componentes específicos: a) nossa proficiência na língua; b) nossa compreensão cultural e da língua em si; e c) nossa habilidade pedagógica. Portanto, a investigação sobre tradução no sentido de desenvolver um estudo comparativo das duas línguas pode contribuir para tal proficiência, compreensão e habilidade pedagógica.

\section{Tradução e o ensino de línguas estrangeiras}

Os pontos apresentados até o momento colaboram para uma visão sobre tradução que vai de encontro com o Método Gramática e Tradução. A visão descrita anteriormente apresenta a tradução como atividade facilitadora no ensino de línguas estrangeiras e não como mera interferência negativa da língua materna. Como Malmkjaer (1998, p. 1) defende: “A tradução continua sendo um componente significativo no ensino de línguas em vários países. Por esta razão, devemos utilizá-la da melhor maneira possível.” A questão, a partir de agora, é saber como desenvolver tal uso.

A utilização da tradução no ensino de línguas estrangeiras (LE) é um campo de interesse nos Estudos da Tradução, devido ao fato de haver a necessidade de se investigar como a tradução pode contribuir para a aquisição e aprendizado da língua estrangeira estudada. É comum observar alunos criando textos e discursos orais de língua inglesa utilizando estruturas de língua materna, tornando a comunicação difícil ou ininteligível, pois tais alunos não têm domínio ou conhecimento suficiente da língua estrangeira.

No início do aprendizado de língua estrangeira, é comum que os alunos recorram à língua materna e haja a influência da mesma, sendo tal influência considerada uma interferência negativa por professores em geral, no contexto de língua estrangeira. Entretanto, a influência da língua materna no aprendizado de LE pode ser aproveitada para apresentarmos particularidades das línguas materna e estrangeira e, aos poucos, fazermos com que o aluno perceba que não é possível haver simetria total entre 
as línguas. Neste caso, busca-se converter a interferência, considerada a princípio negativa, em positiva.

Partindo do campo da interferência para a cognição, Jakobson (1958/2000) destaca que havendo deficiência cognitiva para a transmissão de uma mensagem em um determinado código linguístico, há a possibilidade de utilizarmos a língua para que esta explique seus próprios termos, em uma forma metalinguística de construção de ideias. Esse é um caso comum entre estudantes de línguas estrangeiras que já têm um domínio maior de vocabulário da língua estudada e, mesmo que sintam dificuldade no domínio das palavras e estruturas, vão utilizando a linguagem já adquirida para explicar o que querem dizer. Por exemplo, uma criança norte americana, em contexto brasileiro, conversando com brasileiros, usou a expressão "aquele pássaro que fala" para designar "papagaio". O autor segue explicando que a "terminologia pode ser limitada, de alguma forma, e explicitada por empréstimos linguísticos, neologismos ou mudanças semânticas, ou ainda, por circunlocuções" "(JAKOBSON, 1958, in VENUTI, 2000, p. 115). Assim, alunos iniciantes podem fazer uso, a princípio não positivo, de interlíngua e criar estruturas advindas da língua materna, dificultando a compreensão de suas ideias. Um exemplo foi o uso do termo "Second" por uma aluna, em vez de "According to", em uma apresentação de seminário de língua inglesa. A aluna queria se referir a determinado autor e, ao fazê-lo, utilizou o numeral ordinal, numa referência à língua materna, criando uma mudança semântica inadequada, apesar de compreensível, pelo fato de se tratar de um ambiente onde todos eram falantes da mesma língua materna. Em língua portuguesa, é possível usar a expressão "Segundo" para fazer referência ao que foi dito por alguém.

Seguindo os princípios demonstrados acima, Jakobson (1958/2000, p. 114) utiliza três categorias de tradução, a saber:

1. Intralingual: interpretação de signos verbais através de outros signos da mesma língua.

2. Interlingual: interpretação de signos verbais através de outra língua.

3. Intersemiótica: tradução ou 'transmutação' - interpretação de signos verbais através de sistemas de signos não-verbais (VENUTI, 2000, p. 114).

\footnotetext{
1 terminology may be qualified and amplified by loan-words or loan-translations, neologisms or semantic shifts, and finally, by circumlocutions (VENUTI, 2000, p. 115).
} 
Como pode ser observado, o autor vai além da tradução de textos verbais de uma língua para outra, sugerindo que a tradução acontece dentro da mesma língua, com uso de paráfrase ou circunlocução, por exemplo. A utilização de figuras e expressões faciais são possibilidades de tradução intersemiótica. Já a tradução entre línguas pode ocorrer em situações e atividades específicas, sem causar prejuízo ao desenvolvimento do trabalho de sala de aula, desde que bem preparada e com objetivos claros, tanto para o professor quanto para o aluno. Nesse caso, é possível reforçar a ideia do autor sobre o fato de que a função cognitiva da língua não depende apenas de padrões gramaticais, mas de operações metalinguísticas. Pensando nesses aspectos, podemos ver o ambiente de sala de aula de línguas estrangeiras por outro ângulo mais abrangente e não tentar reprimir o aluno em sua forma de pensar e trabalhar as línguas envolvidas no processo. Ao ordenar ao aluno que "não pense em sua língua materna", estamos exigindo uma função impossível, uma vez que é na língua materna que o aluno tem a construção de suas ideias estabelecidas e, a partir dela, vai construindo seu conhecimento e utilização da língua estrangeira estudada. Isso acontece pelo fato de que "o nível cognitivo da língua não apenas admite, mas exige a interpretação decodificada, isto é, a tradução ${ }^{2,}$ (JAKOBSON, 1958/2000, p. 116) de ideias, frases, palavras, da forma de pensar e agir de uma determinada comunidade.

Gutt (2000, p. 376), por sua vez, faz uma leitura da tradução como sendo um uso interpretativo interlingual. Ou seja, o autor sugere que a tradução seja tratada como um texto numa língua alvo que se assemelhe à língua original de forma interpretativa. Para comprovar seu ponto de vista, o autor apresenta exemplos não diretamente relacionados à tradução interlingual, mas à intralíngua; isto é, exemplo de circunlocução ou paráfrase, seguindo as ideias de Jakobson. Um dos exemplos situacionais mostra duas pessoas conversando sobre uma palestra que uma delas não pôde frequentar e pergunta ao colega que foi à palestra o que foi discutido na mesma. Nesse momento, Gutt oferece várias possibilidades de resposta, dependendo de questões de relevância em geral e do que se acredita que o interlocutor consideraria relevante como resposta. Transferindo essa ideia para o contexto de sala de aula de línguas estrangeiras, o professor costuma ter atitudes semelhantes: há a busca de traduções intralinguais, usos de perífrase, tradução intersemiótica, até que, em caso necessário, utiliza-se a tradução interlingual.

\footnotetext{
2 the cognitive level of language not only admits but directly requires recoding interpretation, i.e., translation (apud VENUTI, 2000, p. 116).
} 
Entretanto, o professor deve estar preparado para considerar questões de relevância e de necessidade de utilizar as possibilidades à sua frente e escolher a que lhe parecer mais relevante ou de melhor solução no momento, levando em consideração a aprendizagem e fixação de conhecimento, além do fator economia de tempo.

É importante lembrar que questões de relevância não podem se confundir com o objetivo traçado para uma determinada aula. Se há um conteúdo a ser trabalhado, não vale a pena utilizar tradução interlingual com a única finalidade de "poupar tempo". É necessário que haja um trabalho cognitivo por parte dos alunos, para que eles passem a entender e dominar os conteúdos trabalhados e, finalmente, possam utilizá-los com mais segurança. Ao traduzir automaticamente, como no Método Gramática e Tradução, não há esforço por parte do aluno, que costuma receber as traduções prontas do professor, gerando acomodação e pouco desenvolvimento linguístico por parte do aluno.

Gutt (2000) cita Sperber e Wilson (1998, p. 137) para afirmar que, ao fazer uso interpretativo da língua, o falante procura se assegurar de que o que diz transmite uma representação suficientemente próxima, em termos de significado, da ideia original - no nosso caso, da ideia em língua materna -, levando em conta questões de relevância. Mais uma vez, transferindo tal afirmação para o ambiente de sala de aula, podemos pensar no aluno tentando se comunicar na língua estrangeira, mas ainda preso às estruturas de sua língua materna. O aluno vai, então, buscando construir suas ideias comparando as estruturas da língua estrangeira com as de língua materna, de forma que elas se pareçam - em forma e significado. É aí que o professor deve iniciar o trabalho de distinção entre as línguas, apresentando as particularidades das estruturas de língua materna e estrangeira, para que o aluno passe, dentro do processo de aquisição de língua, a fazer utilização de proximidade de significado e não de estruturas linguísticas.

Gutt (2000, p. 377) acrescenta que o uso interpretativo em tradução deve assemelhar-se à língua de origem em termos da relevância à audiência, oferecendo efeitos contextuais adequados, sem causar qualquer tipo de esforço de processamento de informação por parte de tal audiência. Isso reforça a ideia de tradução como comunicação. Ou seja, no aprendizado de línguas, temos que aprender a utilizar a língua estudada para comunicação e para transmitir mensagens, partindo de uma cultura já interiorizada - a cultura de língua materna. A questão interpretativa levantada por Gutt parece pertinente nesse aspecto. A seguir, traremos exemplos de atividades com alunos envolvendo o uso de estratégias de tradução utilizadas, inconscientemente, por eles. 


\section{Analisando Estratégias de Tradução utilizadas por alunos em sala de aula de LE}

Esta seção será dividida em duas partes: 1) Explicação de Estratégias de Tradução, segundo Chesterman (1997, 2000); e 2) Descrição e análise de estratégias utilizadas por alunos iniciantes na aprendizagem de língua inglesa.

\section{Estratégias de tradução de acordo com Chesterman (1997)}

Na área de Estudos da Tradução, Chesterman³ (1997) aponta que significados não são mais vistos de acordo com uma visão tradicional e convencional, como sendo algo objetivo, estável, que existe fora de um determinado contexto. Os significados em contexto de tradução são, na verdade, mutáveis, apresentam deslizes, nunca são originais; são sempre relativos. Esta afirmação ilumina a visão da tradução que se pretende lançar aqui - uma visão funcional, descritiva, que vai além da estrutura, significado e propósito imediatos do texto original, sem foco em estruturas linguísticas.

Chesterman (1997) apresenta duas classes de estratégias como sendo principais: 'estratégias de redução', que mudam ou reduzem a mensagem de alguma forma, e 'estratégias de realização', que buscam preservar a mensagem mudando o meio, tal como o uso de paráfrase, aproximação, reestruturação, etc. O autor parece favorecer um tipo de tradução que oferece maior liberdade para a produção de uma tradução, reduzindo informações ou utilizando outra estratégia (parafraseando, reestruturando, etc.) para chegar a um texto-alvo que comunique a mensagem de maneira satisfatória, como descrito por Jakobson e Gutt acima. A seguir, apresentamos a definição de Chesterman para estratégias de tradução utilizada neste trabalho e, em sequência, a taxonomia de estratégias de tradução do autor (ibid., p. 92), dividida em três grupos.

Estratégia é um processo que oferece uma solução para um problema de tradução através de manipulação textual explícita.

\footnotetext{
${ }^{3}$ Meanings are no longer seen as primarily conventional, objective, stable, existing 'out there'; rather, they are ever-shifting, everslippery, never original, always relative (CHESTERMAN, 1997, p. 29).
} 


\begin{tabular}{|c|c|}
\hline \multicolumn{2}{|l|}{ Estratégias Sintáticas } \\
\hline G1: Tradução Literal & $\begin{array}{l}\text { O mais próximo possível da estrutura gramatical do texto de } \\
\text { origem. }\end{array}$ \\
\hline G2: Empréstimo, Calque & Escolha deliberada e consciente. \\
\hline G3: Transposição & $\begin{array}{l}\text { Qualquer mudança de classe de palavra, de substantivo para } \\
\text { verbo, de adjetivo para advérbio. }\end{array}$ \\
\hline G4: Deslocamento de Unidade & $\begin{array}{l}\text { Uma unidade do texto de origem (morfema, palavra, frase, } \\
\text { oração, sentença, parágrafo) traduzida como uma unidade } \\
\text { diferente no texto de chegada. }\end{array}$ \\
\hline $\begin{array}{l}\text { G5: Mudança Estrutural da } \\
\text { Frase }\end{array}$ & $\begin{array}{l}\text { Uma série de mudanças no nível da frase, incluindo número, } \\
\text { exatidão e modificação na oração substantiva, pessoa, tempo } \\
\text { e modo verbal. }\end{array}$ \\
\hline $\begin{array}{l}\text { G6: Mudança Estrutural da } \\
\text { Oração }\end{array}$ & $\begin{array}{l}\text { Mudanças na estrutura da oração em si, tratando de suas } \\
\text { frases constituintes. }\end{array}$ \\
\hline $\begin{array}{l}\text { G7: Mudança Estrutural de } \\
\text { Período }\end{array}$ & Está relacionada à estrutura da unidade da sentença. \\
\hline G8: Mudança de Coesão & $\begin{array}{l}\text { Está relacionada à referência intratextual, elipse, substituição, } \\
\text { pronominalização e repetição ou o uso de conectores de } \\
\text { vários tipos. }\end{array}$ \\
\hline G9: Deslocamento de Nível & $\begin{array}{l}\text { O modo de expressão de um determinado item muda de um } \\
\text { nível (fonológico, morfológico, sintático e lexical) para } \\
\text { outro. }\end{array}$ \\
\hline G10: Mudança de Esquema & $\begin{array}{l}\text { Tipos de mudanças que tradutores incorporam na tradução de } \\
\text { esquemas retóricos, tais como paralelismo, repetição, } \\
\text { aliteração, ritmo, métrica, etc. }\end{array}$ \\
\hline \multicolumn{2}{|l|}{ Estratégias Semânticas } \\
\hline S1: Sinonímia & $\begin{array}{l}\text { Seleciona não o equivalente óbvio, mas um sinônimo ou um } \\
\text { termo 'quase-sinônimo'. }\end{array}$ \\
\hline S2: Antonímia & $\begin{array}{l}\text { O tradutor seleciona um antônimo e o combina com um } \\
\text { elemento de negação. }\end{array}$ \\
\hline S3: Hiponímia & Mudanças na relação hiponímica. \\
\hline S4: Conversão & $\begin{array}{l}\text { Pares de estruturas (geralmente) verbais que expressam a } \\
\text { mesma ideia, mas de pontos de vista opostos, tal como } \\
\text { 'comprar' e 'vender'. }\end{array}$ \\
\hline
\end{tabular}




\begin{tabular}{|c|c|}
\hline S5: Mudança de Abstração & $\begin{array}{l}\text { Uma seleção de nível de abstração diferente, podendo variar } \\
\text { de abstrato para mais concreto ou de concreto para mais } \\
\text { abstrato. }\end{array}$ \\
\hline S6: Mudança de Distribuição & $\begin{array}{l}\text { Mudança na distribuição dos 'mesmos' componentes } \\
\text { semânticos para mais itens (expansão) ou menos itens } \\
\text { (compressão). }\end{array}$ \\
\hline S7: Mudança de Ênfase & $\begin{array}{l}\text { Acrescenta, reduz ou altera a ênfase ou foco temático, por } \\
\text { uma razão qualquer. }\end{array}$ \\
\hline S8: Paráfrase & $\begin{array}{l}\text { Resulta em uma versão do texto de chegada que pode ser } \\
\text { descrita como distante do texto de origem, em alguns casos } \\
\text { até sem tradução. Componentes semânticos no nível do } \\
\text { lexema tendem a ser ignorados, favorecendo a ideia } \\
\text { pragmática de alguma outra unidade, como por exemplo, } \\
\text { uma oração inteira. }\end{array}$ \\
\hline S9: Mudança de Tropos & Tradução de tropos retóricos (ex. expressões figurativas). \\
\hline $\begin{array}{l}\text { S10: Outras Mudanças } \\
\text { Semânticas }\end{array}$ & $\begin{array}{l}\text { Incluindo outras modulações de vários tipos, tais como a } \\
\text { mudança de sentido (físico) ou direção dêitica. }\end{array}$ \\
\hline \multicolumn{2}{|l|}{ Estratégias Pragmáticas } \\
\hline Pr1: Filtro Cultural & $\begin{array}{l}\text { Também tratada como naturalização, domesticação ou } \\
\text { adaptação. }\end{array}$ \\
\hline Pr2: Mudança de Explicitação & $\begin{array}{l}\text { Mais direcionada à informação explícita, ou mais direcionada } \\
\text { à informação implícita. }\end{array}$ \\
\hline Pr3: Mudança de Informação & $\begin{array}{l}\text { Adição de nova informação considerada relevante ao texto de } \\
\text { chegada, mas que não está presente no texto original ou a } \\
\text { omissão de informações presentes no texto original } \\
\text { consideradas irrelevantes. }\end{array}$ \\
\hline Pr4: Mudança Interpessoal & $\begin{array}{l}\text { Altera o nível de formalidade, o grau de emotividade e } \\
\text { envolvimento, o nível de léxico técnico e assim por diante; o } \\
\text { que quer que envolva mudança na relação entre texto/autor e } \\
\text { o leitor. }\end{array}$ \\
\hline Pr5: Mudança de Elocução & $\begin{array}{l}\text { Ligada a outras estratégias: mudança do modo verbal do } \\
\text { indicativo para o imperativo, mudança de afirmação para } \\
\text { pedido. }\end{array}$ \\
\hline Pr6: Mudança de Coerência & $\begin{array}{l}\text { Organização lógica da informação no texto, no nível } \\
\text { ideacional. }\end{array}$ \\
\hline
\end{tabular}




\begin{tabular}{|l|l|}
\hline Pr7: Tradução Parcial & $\begin{array}{l}\text { Qualquer tipo de tradução parcial, tais como tradução } \\
\text { resumida, transcrição, tradução apenas de sons e assim por } \\
\text { diante. }\end{array}$ \\
\hline Pr8: Mudança de Visibilidade & $\begin{array}{l}\text { Mudança na presença de autoria; ou a inclusão evidente ou } \\
\text { em primeiro plano da presença tradutória. Por exemplo, notas } \\
\text { de rodapé do tradutor, comentários entre chaves ou } \\
\text { comentários adicionais explícitos. }\end{array}$ \\
\hline Pr9: Reedição & $\begin{array}{l}\text { A reedição às vezes radical que tradutores precisam fazer } \\
\text { com relação a textos originais mal escritos. }\end{array}$ \\
\hline $\begin{array}{l}\text { Pr10: Outras } \quad \text { Mudanças } \\
\text { Pragmáticas }\end{array}$ & $\begin{array}{l}\text { Mudanças no layout do texto, por exemplo, ou na escolha } \\
\text { dialetal. }\end{array}$ \\
\hline
\end{tabular}

Quadro 1: Estratégias de Tradução de Chesterman (1997)

Partindo das estratégias sintáticas, semânticas e pragmáticas de Chesterman, serão apresentados alguns exemplos de colocações de alunos para que seja possível a verificação de quais estratégias eles utilizam com maior frequência em textos escritos.

\section{Descrição e análise de estratégias utilizadas por alunos iniciantes na aprendizagem de língua inglesa}

Os alunos de língua inglesa que contribuíram nessa fase do nosso estudo, ainda em andamento, estão em nível intermediário na Universidade Federal de Campina Grande (UFCG) e não foram apresentados a qualquer uma das estratégias de tradução. O objetivo de tais alunos é o aprendizado da língua inglesa para comunicação, viagens e ascensão profissional. Portanto, o nosso propósito é de introduzir o uso de estratégias de tradução não para traduzir profissionalmente, mas para mostrá-las como mais uma ferramenta que auxilie no processo de aquisição de língua estrangeira. A princípio, o aluno não precisa ter conhecimento das estratégias ou a consciência de que está utilizando as mesmas em suas atividades de fala ou escrita. No entanto, o professor precisa de tal conhecimento e consciência para que possa utilizar a tradução da melhor forma possível, como ressalta Malmkjaer (1998).

Uma das atividades desenvolvidas com os alunos foi a criação de frases que trabalhassem a utilização de adjetivos estudados. Ou seja, ao desenvolver a atividade, os 
alunos já conheciam os adjetivos a serem usados e estavam familiarizados com a estrutura de língua inglesa, que utiliza o adjetivo antes do substantivo e não pluraliza tal classe gramatical. Entretanto, mesmo com essa informação, alguns alunos mantiveram a estrutura de língua materna, posicionando o adjetivo depois do substantivo, ou ainda utilizando forma plural para os mesmos, fazendo um uso de tradução interlingual inadequado, como é possível observar abaixo:

\section{Exemplo 1:}

a) "My brother lives in a house very large."

b) "Top models are weaks."

Na letra (a), é possível observar o uso de estratégias de tradução literal (G1) e mudança estrutural do período, quando o aluno mantém a organização estrutural da frase como em língua materna: sujeito, verbo, complemento composto por substantivo e adjetivo. A letra (b), por sua vez, apresenta também a estratégia literal (G1) e mudança de esquema (G10), por ter sido acrescentado o plural ao adjetivo. Os exemplos seguintes, entretanto, mostram um uso mais preciso e consciente da estrutura de língua inglesa, fazendo com que as estratégias pareçam com uso mais adequado:

Exemplo 2:

c) "The older are more experienced."

d) "The film was very interesting today."

No exemplo (c), pode-se perceber o uso de estratégia literal no termo 'the older', representando o uso de interlíngua relacionado ao termo de língua materna 'os mais velhos'. O restante da frase e o uso de adjetivo, no entanto, foram feitos adequadamente. O exemplo (d) apresenta organização estrutural da frase adequada e a aplicação do adjetivo não apresentou problemas, provavelmente porque a estrutura usada com verbo de ligação é semelhante ao de língua materna. Sendo assim, o uso de interlíngua não apresentou problema, pela semelhança de estrutura de língua inglesa e materna.

Os exemplos a seguir estão relacionados à outra atividade proposta. Dessa vez, os alunos deveriam escrever um parágrafo descrevendo um lugar relacionado à infância deles, com descrição da importância de tal lugar para suas vidas. Nesse caso, os alunos optaram por deixar termos de língua materna na redação, pois eram termos relacionados a brincadeiras e nomes de lugares. Foi interessante perceber o desenvolvimento dos parágrafos e do domínio de escrita deles, talvez por se tratar de um tema que os envolveu, motivando a produção. 


\section{Exemplo 3:}

e) 'Being a quiet street where we played on the sidewalks 'amarelinha', 'adedonha', 'bolinha de sabão', 'baleado', 'elástico', 'elefante colorido', 'esconde-esconde', among other games."

f) "I remember the Rua Fernando Delgado in João Pessoa where I lived with my parents for 17 years."

O exemplo (e) apresenta o uso da estratégia de empréstimo (G2), já que o aluno optou pela permanência dos termos de língua materna 'amarelinha', 'adedonha', 'bolinha de sabão', 'baleado', 'elástico', 'elefante colorido', 'esconde-esconde'. Houve também o uso de mudança estrutural de período (G7), com a inversão da ordem entre o objeto da frase - 'amarelinha', 'adedonha', 'bolinha de sabão', 'baleado', 'elástico', 'elefante colorido', 'esconde-esconde' - e o advérbio de lugar - 'on the sidewalks'. Nessa atividade, não houve a intenção de corrigir todas as estruturas sintáticas, como tais inversões ou o uso do gerúndio 'being', ou ainda o uso de interlíngua 'on the sidewalks', mas avaliar a capacidade de expressão sem gerar comprometimento da compreensão textual ou, nas palavras de Gutt (2000), oferecendo efeitos contextuais adequados, sem causar qualquer tipo de esforço de processamento de informação.

Como pode ser observado pelos exemplos acima, há a predominância das estratégias sintáticas, com grande utilização da estratégia literal. Isto é explicado pelo fato de que estes alunos estão na fase de descobrimento da língua estrangeira estudada e com as estruturas da língua materna ainda em mente, servindo de suporte a tal aprendizado. Essa influência não pode simplesmente ser negligenciada ou deixada de lado. Há a necessidade de utilizar tal conhecimento e uso de interlíngua a favor do aprendiz. É com este intuito que esta pesquisa dá, agora, seus primeiros passos.

\section{Considerações Finais}

A proposta seminal apresentada neste artigo buscou analisar a sugestão de trabalho com estratégias de tradução para o ensino de línguas estrangeiras. Os exemplos expostos reforçam o ponto de vista de Albir (1998) de que exercícios com tradução geram compreensão, entendimento da ideia e desverbalização do texto, tendo em mente o significado. Com essa colocação, reforçamos também a busca por uma melhor forma 
de re-expressar pensamentos e construções da língua materna em LE. Para tanto, as atividades devem, de fato, envolver aspectos linguísticos e não linguísticos para que os alunos percebam a necessidade de adequar a linguagem a cada texto, contexto e situação. A intenção é de desenvolver o léxico, a visão crítica e aspectos culturais das línguas envolvidas, seguindo as categorias de tradução propostas por Jakobson, a Teoria da Relevância de Gutt, envolvendo a tradução como uso interpretativo interlingual, e as estratégias de tradução de Chesterman.

Apesar deste estudo estar em fase inicial, podemos observar que é possível criar a consciência do professor de LE para a tradução como auxiliar na aquisição de LE, desenvolvendo uma análise comparativa entre as línguas inglesa e portuguesa para um maior desenvolvimento do conhecimento sintático, semântico e pragmático dos alunos em ambas as línguas.

\section{Referências}

ALBIR, Hurtado. La traducción en la enseñanza comunicativa. Cable: Revista de Didáctica del Español como Lengua Extranjera. Madrid, 1998. p. 42-45.

CHESTERMAN, Andrew. Memes of translation: the spread of ideas in translation theory. Amsterdam: John Benjamins, 1997.

COSTA, Walter. Tradução e ensino de línguas. In: BOHN Hilário.; VANDRESEN, Paulino (Eds.). Tópicos de lingüística aplicada ao ensino de línguas estrangeiras. Florianópolis: Editora da UFSC, 1988.

GUTT, Ernst-August. Translation as interlingual interpretive use. In: VENUTI, Lawrence (Ed.). The translation studies reader. London: Routledge, 2000. p. 376396.

JAKOBSON, Roman. On linguistic aspects of translation. In: VENUTI, Lawrence (Ed.). The translation studies reader. London: Routledge, 2000. p. 113-118.

LEFFA, Vilson. Metodologia do ensino de línguas. In: BOHN Hilário. Inácio; VANDRESEN, Paulino. Tópicos em lingüística aplicada: o ensino de línguas estrangeiras. Florianópolis: Ed. da UFSC, 1988. p. 211-236.

LUCINDO, Emy. (1997). Tradução, lexicografia e ensino de línguas. Disponível em:

$<$ http://www.journal.ufsc.br/index.php/scientia/search/authors/view?firstName=Emy $\&$ middleName $=$ Soares\&lastName=Lucindo\&affiliation $>$. Acesso em abril de 2009. 
MALMKJAER, Kirsten. Translation and language teaching. Language teaching and translation. UK: St. Jerome, 1998.

MEDGYES, Peter. The non-native teacher. London: MacMillan, 1994.

SPERBER, Dan.; WILSON, Deirdre. Representation and relevance. In: KEMPSON, Ruth (Ed.). Mental representations: the interface between language and reality. Cambridge: Cambridge University Press, 1998. p. 133-153. 